\title{
Development of neurocognitive disorders in HIVIAIDS
}

This article was published in the following Dove Press journal:

Neurobehavioral HIV Medicine

9 March 201 I

Number of times this article has been viewed

\author{
Brandon C Dennis ${ }^{1,2}$ \\ Sidney A Houff' \\ Dong Y Han' \\ Frederick A Schmitt ${ }^{1,2,3}$ \\ 'Department of Neurology, \\ ${ }^{2}$ Sanders-Brown Center on Aging, \\ ${ }^{3}$ Departments of Psychiatry, \\ Psychology, and Behavioral Science, \\ University of Kentucky College of \\ Medicine, Lexington, KY, USA
}

\begin{abstract}
The introduction of highly active antiretroviral therapy has had an enormous impact on the management of human immunodeficiency virus (HIV) infection and has led to an increase in survival and decrease in HIV-associated dementia. However, minor neurocognitive disturbances across various neurocognitive domains remain common in $50 \%$ or more of HIV patients according to recent estimates. Increased longevity has led to the investigation of several moderating and complicating factors, including vascular disease, neurotoxicity, aging, substance abuse, hepatitis $\mathrm{C}$ coinfection, and psychiatric illness. This article provides a review of the history of HIV-associated neurocognitive disorders (HAND), revised diagnostic terminology, factors moderating development of HAND, assessment techniques and neurocognitive profiles, current treatment and limitations, and future research directions.
\end{abstract}

Keywords: HIV-associated neurocognitive disorders, HIV dementia, AIDS dementia, AIDS

\section{Introduction}

Since the Centers for Disease Control and Prevention's (CDC) publication of the first article describing a pattern of opportunistic infection that would later become known as acquired immunodeficiency syndrome (AIDS) in 1981, ${ }^{1}$ human immunodeficiency virus (HIV) continues to be a public health threat that affects between 30 and 40 million people worldwide and over 1.1 million people in the United States alone. ${ }^{2,3}$ With the introduction of zidovudine (also known as azidothymidine or AZT) in 1987 came the first antiretroviral (ARV) agent to effectively combat HIV and improve cognition in both adults and children with AIDS. ${ }^{4-6}$ However, it was the transition from monotherapy or dual therapy to highly active antiretroviral therapy (HAART) in 1996 that resulted in suppression of HIV-1 viral load, slowed progression of HIV infection, and contributed to an increased quality of life for HIV-positive persons. ${ }^{7-9}$ This treatment advance transformed the disease from one that was almost certainly fatal in fewer than 6 months to one that permitted patients to live into the 6 th and 7 th decades of life and beyond. ${ }^{10,11}$ HAART has also dramatically reduced the incidence of severe HIV-associated dementia (HAD) from $>50 \%$ of patients in the pre-HAART era to recent reports of $2 \%-8 \%$ in two cohorts. ${ }^{12,13}$ Unfortunately, HIV-associated neurocognitive disorders (HAND), especially milder forms, persist with estimates that between $30 \%$ and $60 \%$ of HIV-positive persons will experience at least mild neurocognitive disturbance. ${ }^{14,15}$ The CNS HIV Antiretroviral Therapy Effects Research (CHARTER) study, a multisite US cohort, recently found that $52 \%$ of their total sample had neurocognitive impairment, with milder forms
Correspondence: Brandon C Dennis Department of Neurology, University of Kentucky College of Medicine, 740 S Limestone St, Ste L-445, Lexington, KY 40536-0284, USA

$\mathrm{Tel}+\mathrm{I} 859218505$ I

Fax +I 8593233753

Email brandoncdennis@uky.edu 
occurring more frequently. ${ }^{12}$ Swiss researchers recently found the prevalence of HAND in their cohort to be between $64 \%$ and $84 \%$, even among aviremic patients, depending on whether or not a cognitive complaint was present. ${ }^{13}$ Despite discrepancies in prevalence estimates, studies confirm that HAND continues to be a concern despite effective ARV treatment and shed light on some emerging potential complicating factors. This article provides a review of HAND, historic and evolving diagnostic criteria and course of illness, moderating variables, diagnostic procedures and biomarkers, treatment and emerging complications in the HAART era, and patterns of neurocognitive deficit.

\section{Diagnosis and classification of HAND}

The decline in neurocognitive functioning and frequent motor and behavioral dysfunction accompanying the onset of HIV infection was initially termed AIDS dementia complex (ADC) and was observed in nearly two-thirds of autopsies in one sample. ${ }^{16}$ In 1991, the Working Group of the AIDS Task Force of the American Academy of Neurology (AAN) published the first research criteria for HAND to better distinguish subtypes of cognitive dysfunction. ${ }^{17}$ HAD was reserved for the most severe cases of cognitive disturbance with cognitive, motor, and/or emotional disturbances. In contrast, HIV-associated minor cognitive motor disorder (MCMD) was applied to less severe cases producing less impact on daily living. ${ }^{15}$ The AAN diagnostic criteria required the patient to have the following: 1) exhibit objective impairment in at least two cognitive domains (eg, memory, attention, language, and processing speed), 2) show impairment in performance of activities of daily living (ADL), 3) experience either motor impairment or impaired emotional control or changes in social behavior, 4) have an absence of 'clouding of consciousness', and 5 ) exclusion of alternate neurological disorders. Objective evidence of cognitive impairments is provided by standardized mental status and cognitive testing. ${ }^{18} \mathrm{~A}$ revision of the criteria and diagnostic nosology emerged from a 2007 working group supported by the US National Institutes of Health, with more emphasis being placed on the documentation of neurocognitive disturbance to distinguish HAND subtypes. ${ }^{15}$ These revisions produced criteria for diagnosis of three subtypes of cognitive impairment: HAD, HIV-associated mild neurocognitive disorder (supplanting the previous MCMD), and the addition of asymptomatic neurocognitive impairment. ${ }^{19}$

\section{HAND in the pre- and post-HAART eras}

Progression to dementia is more common in the later stages of HIV infection. ${ }^{20}$ Although neurocognitive disturbances may be present, dementia in the asymptomatic phase of infection is uncommon. Sacktor and colleagues ${ }^{21}$ compared data from two large cohort studies: the Dana Cohort, ${ }^{22}$ including persons primarily on mono or dual ARV therapy, and the Northeastern AIDS Dementia (NEAD) Cohort ${ }^{23}$ with persons primarily on HAART regimens (ie, two or more ARV drugs plus a protease inhibitor [PI]). Results suggest a greater percentage of persons with HIV-minor cognitive/motor disorder among the Dana when compared with the NEAD Cohort (47.7\% vs $37.4 \%, P=0.10$ ), but roughly equivalent percentages of persons with HIV dementia (27.3\% vs $32.1 \%, P=0.17)$. The authors caution that this finding should not indicate a failure of HAART to improve cognitive outcome, rather they believe it was a function of the members of both cohorts being recruited because they were at high risk for HIV dementia. ${ }^{21}$ More recently, Vivithanaporn and colleagues ${ }^{24}$ examined data on neurological disorders over a 10 -year period post-HAART therapy initiation. They found that HAND was the second most common neurological disorder behind distal sensory polyneuropathy and confirmed that AIDS-diagnosed individuals had a much higher incidence of all neurologic disorders than did HIV-positive people without AIDS (41\% vs $19.9 \%, P<0.0001)$. Viral load and cell count were associated with an increased risk of mortality. ${ }^{24}$ Other data, such as those from the Multicenter AIDS Cohort Study (MACS), have estimated that HAART may have reduced the incidence of HIV dementia anywhere from $15 \%$ to $50 \%{ }^{25}$ and have likely changed the manifestations of HAND to a milder severity with mixed subcortical and cortical features, higher CD4 cell counts, and variable patterns of progression. ${ }^{26}$

\section{Clinical manifestations and course of HAD}

Development of the ADC, as it was originally conceptualized, was believed to be stereotypic, subcortical in nature, and progressive over several months, sometimes arising as the presenting problem and sole manifestation of otherwise asymptomatic $\mathrm{HIV}^{27}$ In the post-HAART era, the course of dementia progression has become more heterogeneous and appears to be related to factors such as retroviral therapy adherence, aging, substance abuse, and other 
psychosocial factors. Nath and colleagues ${ }^{20}$ have proposed distinctive subtypes of HIV dementia: 1) a 'subacute progressive' dementia, often in untreated individuals and resembling dementia observed pre-HAART; 2) a 'chronic active' dementia, often seen in persons at risk for neurological dysfunction who may be treated with HAART but have viral resistance; 3) a 'chronic inactive' dementia, referring to neurologically stable symptoms due to HAART; and 4) a 'reversible' dementia which remits with good HAART adherence, resulting in effective virological suppression. ${ }^{20,26}$ These concepts appear to be supported by autopsy data that confirmed neuropathological abnormalities, including multinucleated giant cells, considered to be the histopathological hallmark of HIV-1 infection in the brain, in $79 \%-94 \%$ of patients with AIDS. ${ }^{28}$

Survival of patients with HAD has improved considerably since the advent of HAART, with median survival of nearly 2 years, even in patients with low CD4 cell counts. ${ }^{10}$ Without treatment, HIV dementia is rapidly progressive with mean survival rates that are less than half that of nondemented, untreated AIDS cases, at about 6 months. ${ }^{10,29}$

\section{Neurocognitive disturbances in HAND}

Formal, standardized neuropsychological evaluation provides the objective neurocognitive data essential for diagnostic staging, particularly in nondementia HAND. ${ }^{18}$ Hundreds of measures exist to evaluate specific cognitive functions, ${ }^{30}$ and several batteries have been established specifically to evaluate neurocognitive functions in HIV. The MACS group has developed an evaluation procedure consisting of self-report, neuropsychological screening, and physiologic measures. ${ }^{31}$ The neurology section of the AIDS Clinical Trials Group has developed comprehensive and screening procedures, such as the NPZ8 and NPZ4, ${ }^{32}$ and the National Institute of Mental Health workshop on assessment of AIDS patients has proposed an assessment procedure based on the expanded Halstead-Reitan Neuropsychological Battery. ${ }^{33-35}$ For more severe cases of HIV dementia, briefer instruments such as the HIV Dementia Scale, ${ }^{18,36}$ which has been shown to be sensitive and predictive of HAND and superior to the mini-mental state examination, ${ }^{37}$ may be useful. Various neurocognitive domains are typically affected by HIV infection, ranging from higher-order cognitive processing to motor impairment. Recent studies ${ }^{38,39}$ support the existence of several distinct clusters of neurocognitive disturbance among HIV-infected patients.

\section{Memory}

A common cognitive deficit in HAND in general and HAD in particular is impaired memory, especially episodic learning and retrieval of new information. ${ }^{15} \mathrm{HIV}$-seropositive individuals score worse than demographically similar uninfected persons on learning of both verbal and nonverbal material. The pattern of episodic memory impairment most closely fits an encoding and retrieval pattern, which has often led to it being referred to as 'subcortical' in nature. ${ }^{40}$ Prospective memory, which is dependent on frontal systems and involves the formation, maintenance, retrieval, and execution of a future intention, has also been shown to be impaired in HIV-positive individuals. ${ }^{41-43}$

\section{Attention, processing speed, and working memory}

In HIV-infected individuals, impairment of attention, processing speed, and working memory is related to HIV disease severity and difficulty of the task at hand. ${ }^{43}$ Simple attention tends to remain relatively preserved early in the disease process, while tasks involving more complex skills, such as information manipulation, especially under time constraints, are sensitive to HIV effects. ${ }^{44}$ Evidence for HIV effects on working memory remains somewhat unclear, however, with some studies finding evidence of disturbance in short-term memory and immediate manipulation of information ${ }^{45,46}$ and others finding no dysfunction despite changing disease severity. ${ }^{14}$

\section{Executive functioning}

Executive functions, including organizing, planning, and problem-solving, are important for the initiation and carrying out of independent behavior. Meta-analytic and cluster analysis studies have confirmed that HIV infection is associated with executive dysfunction and is likely a component of all HAND profiles. ${ }^{39,44}$ Formal neuropsychological measures have documented deficits in HIV-positive individuals on tasks of reaction time and response inhibition, ${ }^{47,48}$ novel problem-solving, ${ }^{14}$ abstract reasoning, ${ }^{49}$ and set-shifting. ${ }^{44}$ Similar to measures of attention, level of dysfunction is in part dependent on the difficulty of the task at hand. ${ }^{43}$

\section{Language}

Significant speech and language deficits, such as aphasia, are not commonly observed in adult patients with HIV infection. However, expressive language deficits are often observed in children infected with HIV. ${ }^{50}$ Studies of verbal fluency in HIV-positive individuals have been variable, with some 
confirming deficits ${ }^{51,52}$ and others failing to find an effect of HIV on fluency. ${ }^{53,54}$ In a 2007 review, Iudicello and colleagues reported a small but consistent fluency deficit across studies. ${ }^{55}$ Woods and colleagues found that HIV-positive individuals performed poorly on action fluency, (verbal fluency for verbs rather than for letters or nouns) and that this type of fluency may prove to be more sensitive to HAND, and is associated with impairments in the performance of ADL. ${ }^{56}$

\section{Visuospatial skills}

Although initial large-scale investigations detected no significant visuospatial impairment using limited assessment of spatial cognition ${ }^{14}$ and appeared consistent with the relative sparing of the occipital and parietal cortices in AIDS, more recent meta-analyses have shown mixed results. ${ }^{43,44,57}$ Multiple subsequent investigations support the likely existence of subtle visuospatial deficits in HIV infection, while the underlying etiology remains unclear, necessitating continued investigation of visuospatial skills in this population. $^{43}$

\section{Motor skills}

Deficits in motor functioning, including psychomotor processing and motor speed slowing, have been characteristic of HIV infection throughout its course, with more severe motor disorders, such as dystonia, occurring less frequently. ${ }^{58}$ Psychomotor/motor slowing remains a common neurocognitive complaint among HIV patients, and the classification of minor cognitive/motor disorder or minor neurocognitive disorder (including motor) remain among the most frequently observed in cohort-based studies. ${ }^{13,21}$ Sacktor and colleagues have demonstrated an improvement in fine motor speed bilaterally among patients after initiation of HAART when compared to matched controls, suggesting promising effectiveness of HAART on a commonly reported neurocognitive disturbance. ${ }^{59}$

As these findings suggest, neurocognitive deficits may be present in any functional cognitive domain and may be related to a number of factors, such as disease progression, effectiveness of ARV regimen, and co-occurring disorders.

\section{Moderating factors affecting development of HAND}

Because HAART has greatly extended the survival rates of persons with HIV dementia and because of the heterogeneity of cognitive dysfunction with HAART, a number of comorbid and risk factors have been examined as potential contributors to neurocognitive dysfunction with HIV disease. ${ }^{11,60}$

\section{Aging}

According to the CDC, ${ }^{61}$ more than $15 \%$ of AIDS patients are now above the age of 50 years, a rate that has tripled over the past several years. The age range of 45-49 years representing $21 \%$ of infected individuals accounted for the largest age group. With increased longevity comes the risk of traditional age-related medical complications, such as vascular diseases, metabolic disturbances, and neurodegenerative diseases, superimposed on chronic HIV infection. ${ }^{20}$ Prior to HAART, data from the MACS Cohort revealed no effect of age on neuropsychological testing profiles when corrected for serostatus. ${ }^{62}$ However, a more recent study compared demographically and infection-status matched younger and older individuals on measures of neuropsychological functioning and found discrepant results. ${ }^{63}$ The older group of HIV-infected individuals had higher rates of impairment across most ability domains. Viral burden and age were significant predictors of neuropsychological impairment, and together were predictors with a significant interaction between viral burden and age. This suggests that despite more effective ARV treatment, aging continues to be a significant contributor to the onset of neurocognitive impairment, similar to what is seen for other neurodegenerative etiologies. In addition, among the older individuals, those with detectable virus in the cerebrospinal fluid (CSF) had twice the prevalence of neuropsychological impairment of those with undetectable levels. Interestingly, lifetime incidence of major depression, substance abuse, and current depression were not associated with neuropsychological impairment. ${ }^{63}$ Similar increased rates of cognitive dysfunction associated with aging were found in the Hawaii Aging with HIV Cohort. ${ }^{64}$ Comparing normal elderly males to males diagnosed with ADC and males diagnosed with Alzheimer's disease (AD), Van Gorp and colleagues concluded that despite $30+$ years difference, there was a strong similarity between the normal elderly and individuals with ADC in neuropsychological performance. ${ }^{65}$ Patients with AD did remarkably worse than patients with ADC on nearly all measures, suggesting a more subcortical pathogenesis among HIV infection and AIDS.

\section{Vascular diseases}

Cardiovascular and cerebrovascular diseases have emerged as areas of investigation both as sources of cognitive 
impairment and as consequences of HAART and HIV infection itself. Cerebrovascular risk among HIV-positive cases has been associated with slower processing speed and poorer verbal fluency. ${ }^{66} \mathrm{HIV}$-positive persons who were untreated for cerebrovascular risk factors demonstrated reduced processing speed, learning and memory, and executive functioning. ${ }^{66}$ Prior cardiovascular disease has been associated with neurocognitive impairment in controlled studies of HIV-positive individuals. ${ }^{67}$ Cardiovascular disease, hypercholesterolemia, and hypertension were found to be associated with poorer neurocognitive performance, whereas interestingly, traditional HAND risk factors and penetration effectiveness rank of the ARV drugs were not. ${ }^{67}$ This suggests that the use of PIs, an essential component of modern HAART that has been associated with vascular risk (such as increased risk for hypertension ${ }^{68}$ and a $26 \%$ rise in myocardial infarction ${ }^{69}$ ), may predict neurocognitive changes in the long term.

\section{Hepatitis $C$ virus}

The rate of coinfection of HIV and hepatitis C virus (HCV) has been reported as ranging from $15 \%$ to more than $30 \%$ in the United States. ${ }^{61,70,71}$ An estimated $50 \%-90 \%$ of injection drug users are dually infected with HIV-HCV. HCV infection is more serious in HIV-infected persons as liver damage progresses much more quickly, potentially affecting cognition through a metabolic impact on the brain. ${ }^{70}$ Coinfection also may hinder HIV treatment due to liver disease or hepatotoxicity, making prevention and early diagnosis much more important. ${ }^{72}$ However, neurocognitive studies of the effects of coinfection have been challenging because of the frequency of ongoing comorbid substance abuse. ${ }^{11}$ Some studies have demonstrated that coinfected individuals perform poorer compared to persons infected with either virus alone on measures of processing speed, psychomotor speed, and learning efficiency, ${ }^{73}$ while others have failed to find significant differences. ${ }^{74}$ Information on underlying mechanisms remains unclear, as is the evolutionary pattern of the coinfected person's cognitive impairment. Of note, individuals with coinfection often report higher levels of depression and have more severe substance abuse histories, ${ }^{73}$ the latter of which result in neurotoxic effects, depending on substance. ${ }^{75-77}$

\section{Substance dependence}

The World Health Organization has estimated that in areas outside of sub-Saharan Africa, intravenous drug use is responsible for approximately one-third of new HIV infections worldwide and up to $57 \%$ of new cases in Central Asia and Eastern Europe. ${ }^{3}$ Besides accounting for newly infected cases, continued substance abuse has a deleterious effect on overall neurocognition. HIV-infected drug abusers have been shown to have more severe encephalitis at autopsy ${ }^{78}$ and have been shown to have an accelerated onset of dementia. ${ }^{76}$ Other than simple additive effects, synergistic effects have been suggested as effects on immune system functioning, cytokine regulation, damage to cerebrovasculature, and neuronal damage and neurotoxicity via commonly affected neurotransmitter systems, such as glutamatergic and dopaminergic pathways. ${ }^{75} \mathrm{HIV}$ is believed to damage neurons and therefore brain functioning via all of these mechanisms, which vary depending on the substance of abuse. ${ }^{11,75}$ Studies suggest that the dopaminergic system is vulnerable to effects of HIV infection and that intravenous drug abusers with HIV infection had more severe neuronal loss and shrunken neuronal cells in the substantia nigra compared to people who died of AIDS without a history of drug abuse. ${ }^{77,79}$ This suggests that use of drugs such as cocaine, amphetamines, and opiates, all of which have dopaminergic activation properties, may accelerate the loss of an already compromised dopamine system in patients with HIV and may accelerate the onset of HAND. ${ }^{75}$

\section{Psychiatric conditions}

Personality and psychiatric conditions, especially anxiety and depression, may be related to progression of HIV disease to HIV dementia and survival. A history of at least one psychiatric disorder was noted in one study among $88.2 \%$ of HIV-positive but asymptomatic or mildly symptomatic homosexual men, ${ }^{80}$ with rates of generalized anxiety disorder at $39.3 \%$ and rates of major depressive disorder at $30.3 \%$. Depression is common in patients with HIV infection and may be the initial presentation of what later evolves to HIV dementia. ${ }^{81}$ It is common for depression to go unrecognized and untreated in HIV-positive persons, possibly because of difficulty in differentiating it from similar symptoms of fatigue, pain, anorexia, and insomnia. ${ }^{81,82}$ The relationship between HIV dementia and depression is complicated because both affect neurotransmitter functioning (eg, serotonin and dopamine), and individuals with both cognitive dysfunction and depression may not respond well to antidepressant therapy as a result. ${ }^{83}$

\section{Intelligence and education}

Overall intellectual functioning has been shown to be a significant predictor of HIV disease progression and survival. This finding remained constant even when controlling 
for baseline CD4 and HIV medication use. ${ }^{84}$ This is likely related to the fact that in well-developed countries with ready access to medical care, socioeconomic status (SES), through its direct relationship with intelligence, plays a significant role in access to medical care. ${ }^{85}$ Cultural and familial SES factors also play a role. For example, years of research have documented that minorities are less likely to seek out medical treatment and more likely to receive lower quality health care. ${ }^{86}$ Studies also suggest a strong relationship between parental behaviors related to medical care and subsequent utilization of health care by their children. ${ }^{87}$ It is well documented that better-educated people perform better on many neuropsychological tests, which is relevant when considering these tests provide the objective cognitive data for diagnosis and staging of HAND. ${ }^{15}$ It has been observed that those persons with higher intelligence scores and therefore better performance on various measures of cognition maintain mental faculties longer than their counterparts, a phenomenon known as cognitive reserve. ${ }^{88,89}$ This would suggest that demographic and sociocultural factors contribute a disadvantage in the access and possible adherence to treatment for HIV. In turn, these characteristics may lead to differential progression of HIV disease, decreased survival, and an increase in complications, such as HAND.

\section{Biomarkers, structural correlates, and magnetic resonance}

Similar to trends with other neurological illnesses, there is growing interest in identifying biomarkers that are sensitive and specific to HAND in order to provide more accurate diagnosis and clinical staging. ${ }^{90}$ Biomarkers measuring blood or CSF have been examined as markers of effector cells, modulators of pathogenesis, toxins, and target cells..$^{90}$ Although there are many promising biomarkers under investigation, three are available in clinical practice that appear to be related to the presence or potential evolution to HAND. CD4 cell count, a standard measurement to monitor disease progression and ARV effectiveness, is strongly related to HAND diagnosis as counts above 200 cells $/ \mu \mathrm{L}$ are rarely associated with dementia. ${ }^{10,90,91}$ Much less reliable than the CD4 count is the HIV RNA concentration in the CSF, which is limited due to its detectability in various stages of cognitive impairment ${ }^{32}$ as well as normal levels even in the presence of dementia. ${ }^{57}$ Finally, CSF protein levels may be helpful as studies have shown elevated levels of albumin, immunoglobulin G, and total protein in individuals with a diagnosis of HIV dementia. ${ }^{90}$

Magnetic resonance imaging (MRI) and magnetic resonance spectroscopy (MRS) have proven to be useful tools in identifying neuroinflammation, atrophy, and lesion locations among persons with HIV. ${ }^{92}$ MRI in advanced HAD typically shows generalized white matter volume reduction as well as gray matter volume reduction in the basal ganglia and posterior cortex. ${ }^{93-95}$ In earlier stages of infection, prior to the development of dementia, structural abnormalities have been reported in the splenium of the corpus callosum and in the crura of the fornices. ${ }^{96}$ An investigation of MRI and MRS correlates of HIV-associated blood-brain barrier (BBB) compromise revealed that the severity of neurocognitive impairment was associated with the degree of BBB breakdown in the basal ganglia. This showed that individuals with high plasma viral load were more severely impaired, BBB compromise correlated with a marker of neuroinflammation in the basal ganglia, and the severity of BBB compromise and neurocognitive impairment was significantly lower in persons on HAART than in those who were HAART-naive. ${ }^{97}$

An investigation using MRS found significantly increased levels of inflammation and oxidative stress among HIV-positive patients despite HAART. ${ }^{98}$ A more recent study used factor analytic technique to classify and evaluate regional variations in magnetic resonance spectroscopic imaging, resulting in three factors which were effective in differentiating participants with and without dementia. ${ }^{99}$ The 'Cho factor' (choline-based compounds [Cho]) was effective in differentiating normal controls from seropositive participants with signal in the frontal white matter, parietal white matter, centrum semiovale, thalamus, and basal ganglia. The 'NAA factor' ( $N$-acetylaspartate [NAA]) distinguished between demented and nondemented HIV-positive participants with involvement in the frontal and parietal white matter, centrum semiovale, and parietal gray matter. The ' $\mathrm{Cr}$ factor' (creatine and phosphocreatine-containing compounds [Cr]) was influenced by levels from parietal and frontal white matter and centrum semiovale and discriminated seropositive participants from controls, although not significantly. ${ }^{99}$ Similar to other recent findings, ${ }^{12,13,24}$ these studies confirm possible sources of continued neurocognitive dysfunction despite effective viral control with HAART and may be useful in future studies of comorbid conditions in HIV disease. 


\section{Treatment}

The currently accepted treatment strategy for HIV infection is the use of ARV therapy to block activity of the viral reverse transcriptase, protease, and integrase enzymes that permit replication of the viral DNA. ${ }^{100,101}$ Original therapies included monotherapy or dual therapy ARV agents, beginning with the introduction of azidothymidine in $1987 .{ }^{6}$ Because HIV replicates quickly and replication is prone to errors permitting the virus to become quickly resistant to single agents or entire drug classes, the use of multiple drugs in different classes is the most effective strategy to suppress spread of the virus. The current standard is known as HAART, defined as use of three or more drugs, typically two nucleoside reverse transcriptase inhibitors (NRTIs) and a PI or two NRTIs and a non-NRTI. ${ }^{100,101}$

There is considerable heterogeneity among ARV agents in regard to effectiveness of central nervous system (CNS) penetration, which has raised concerns about effectiveness of drug choice and dosing as well as neurotoxicity of some agents. Letendre and colleagues with the CHARTER group devised a CNS penetration effectiveness (CPE) ranking system to classify ARV agents. Lower CPE ranks correlated with higher CSF viral loads, even after adjusting for total number of ARV drugs, ARV adherence, plasma viral load, duration and type of current regimen, and CD4 count. ${ }^{102}$ Greater viral suppression due to CNS penetration may influence survival ${ }^{103}$ and has corresponded to greater neurocognitive improvement. ${ }^{104}$ However, animal models of ARV exposure have implicated nearly all current medication regimens as potentially toxic to cortical neurons. ${ }^{105}$ Another 48-week randomly assigned human trial found that medication regimens containing efavirenz may lead to better normalization of the infected nervous system, but still lead to worsening neurocognitive performance. ${ }^{106}$

As with other causes of dementia, treatment of cognitive and emotional sequelae is symptomatic and focused on prolonging normal cognitive functioning and sustaining one's quality of life. Memory impairment may be responsive to acetylcholinesterase inhibitors, such as those used in the treatment of AD. Use of $N$-methyl-D-aspartate receptor antagonist agents, such as memantine, may serve two purposes. First, they may serve to enhance memory and cognitive functioning, and also to protect against excitotoxic injury by affecting the cytokine signaling within the CNS. ${ }^{107}$ In one study, use of memantine for treatment of HIV-associated cognitive impairment found no significant improvements in neuropsychological performance over the 16-week clinical trial.
However, there was an increase in $\mathrm{N}$-acetylaspartate to creatine ratio in the frontal white matter and parietal cortex that suggests a potential therapeutic benefit. Memantine has also been shown to ameliorate neuronal metabolism on MR spectroscopy studies. ${ }^{108}$ These findings would suggest that initiating treatment for cognitive impairment early in the process may slow decline as it does in other neurodegenerative diseases.

For the treatment of emotional and psychiatric disturbances, traditional psychotherapy or the use of antidepressant medications or combination pharmacotherapy may be useful. ${ }^{2}$ Despite promise for effective management of cognitive and psychiatric complications associated with HIV, there have been few placebo-controlled clinical trials to determine more effective strategies in the presence of HAND.

\section{Conclusion}

HAART has clearly improved the outlook for the HIV-infected individual by decreasing the incidence of HIV dementia and increasing the survival rate. Unfortunately, despite effectiveness of treatment on viral burden and cell counts, neurological conditions persist, with recent studies suggesting $50 \%$ or more of persons will experience some form of neurocognitive dysfunction. These impairments are variable and may represent several distinct patterns of neurocognitive dysfunction. With better management of viral burden, research efforts have been directed at understanding and addressing other complicating factors, such as substance abuse, psychiatric illness, coinfection, and aging. As the survival rate improves and HIV-positive persons live longer, other factors have emerged, including metabolic, neurotoxic, and cardiovascular complications that may hasten or promote the onset of HAD in a manner similar to other neurodegenerative conditions. Improved diagnostic criteria, neuropsychological testing, and new technology, such as biomarker, MRI, and MRS analysis, have advanced our ability to identify and treat HAND. Further research efforts may be directed at delineating the various neurocognitive profiles, identifying and confirming novel treatment options with placebo-controlled clinical trials, and further exploring potential neurotoxic effects of ARV therapy, in combination with public health initiatives aimed at preventing the spread of the disease.

\section{Acknowledgment}

The authors gratefully acknowledge support from the National Institutes of Health, Bethesda, MD (P50 AG05144, R01 AG019241, and R01 HD064993). 


\section{Disclosure}

The authors report no conflicts of interest in this work.

\section{References}

1. Centers for Disease Control and Prevention. Kaposi's sarcoma and Pneumocystis pneumonia among homosexual men - New York City and California. MMWR Morb Mortal Wkly Rep. 1981;30(25): 305-308.

2. Ances BM, Letendre SL, Alexander T, Ellis RJ. Role of psychiatric medications as adjunct therapy in the treatment of HIV associated neurocognitive disorders. Int Rev Psychiatry. 2008;20(1):89-93.

3. AIDS Epidemic Update 2009. Geneva, Switzerland: Joint United Nations Programme on HIV/AIDS (UNAIDS) and World Health Organization (WHO); 2009.

4. Quinn TC, Glasser D, Cannon RO, et al. Human immunodeficiency virus infection among patients attending clinics for sexually transmitted diseases. N Engl J Med. 1988;318(4):197-203.

5. Schmitt FA, Bigley JW, McKinnis R, Logue PE, Evans RW, Drucker JL. Neuropsychological outcome of zidovudine (AZT) treatment of patients with AIDS and AIDS-related complex. $N$ Engl J Med. 1988; 319(24):1573-1578.

6. Moore RD, Keruly J, Richman DD, Creagh-Kirk T, Chaisson RE. Natural history of advanced HIV disease in patients treated with zidovudine. The Zidovudine Epidemiology Study Group. AIDS. 1992;6(7):671-677.

7. Food and Drug Administration, US Department of Health and Human Services. HIV/AIDS historical timeline 1981-1990. Available from: http:// www.fda.gov/ForConsumers/ByAudience/ForPatientAdvocates/ HIVandAIDSActivities/ucm151074.htm. Accessed October 25, 2010.

8. Brodt HR, Kamps BS, Gute P, Knupp B, Staszewski S, Helm EB. Changing incidence of AIDS-defining illnesses in the era of antiretroviral combination therapy. AIDS. 1997;11(14):1731-1738.

9. Powderly WG. Sorting through confusing messages: the art of HAART. J Acquir Immune Defic Syndr. 2002;31 Suppl 1:S3-S9; discussion S24-S25.

10. Dore GJ, McDonald A, Li Y, Kaldor JM, Brew BJ; National HIV Surveillance Committee. Marked improvement in survival following AIDS dementia complex in the era of highly active antiretroviral therapy. AIDS. 2003;17(10):1539-1545.

11. Gonzalez R, Cherner M. Co-factors in HIV neurobehavioural disturbances: substance abuse, hepatitis $\mathrm{C}$ and aging. Int Rev Psychiatry. 2008;20(1):49-60.

12. Heaton RK, Clifford DB, Franklin DR Jr, et al; CHARTER Group. HIV-associated neurocognitive disorders persist in the era of potent antiretroviral therapy: CHARTER Study. Neurology. 2010;75(23): 2087-2096.

13. Simioni S, Cavassini M, Annoni JM, et al. Cognitive dysfunction in HIV patients despite long-standing suppression of viremia. AIDS. 2010;24(9):1243-1250.

14. Heaton RK, Grant I, Butters N, et al. The HNRC 500 - neuropsychology of HIV infection at different disease stages. HIV Neurobehavioral Research Center. J Int Neuropsychol Soc. 1995;1(3):231-251.

15. Grant I. Neurocognitive disturbances in HIV. Int Rev Psychiatry. 2008;20(1):33-47.

16. Navia BA, Jordan BD, Price RW. The AIDS dementia complex: I. Clinical features. Ann Neurol. 1986;19(6):517-524.

17. Nomenclature and research case definitions for neurologic manifestations of human immunodeficiency virus-type 1 (HIV-1) infection. Report of a Working Group of the American Academy of Neurology AIDS Task Force. Neurology. 1991;41(6):778-785.

18. Bottiggi KA, Chang JJ, Schmitt FA, et al. The HIV Dementia Scale: predictive power in mild dementia and HAART. J Neurol Sci. 2007;260(1-2):11-15.

19. Antinori A, Arendt G, Becker JT, et al. Updated research nosology for HIV-associated neurocognitive disorders. Neurology. 2007;69(18): 1789-1799.
20. Nath A, Schiess N, Venkatesan A, Rumbaugh J, Sacktor N, McArthur J. Evolution of HIV dementia with HIV infection. Int Rev Psychiatry. 2008;20(1):25-31.

21. Sacktor N, McDermott MP, Marder K, et al. HIV-associated cognitive impairment before and after the advent of combination therapy. J Neurovirol. 2002;8(2):136-142.

22. Clinical confirmation of the American Academy of Neurology algorithm for HIV-1-associated cognitive/motor disorder. The Dana Consortium on Therapy for HIV dementia and related cognitive disorders. Neurology. 1996;47(5):1247-1253.

23. Marder K, Albert SM, McDermott MP, et al. Inter-rater reliability of a clinical staging of HIV-associated cognitive impairment. Neurology. 2003;60(9):1467-1473.

24. Vivithanaporn P, Heo G, Gamble J, et al. Neurologic disease burden in treated HIV/AIDS predicts survival: a population-based study. Neurology. 2010;75(13):1150-1158.

25. McArthur JC, Sacktor N, Selnes O. Human immunodeficiency virusassociated dementia. Semin Neurol. 1999;19(2):129-150.

26. McArthur JC. HIV dementia: an evolving disease. J Neuroimmunol. 2004;157(1-2):3-10.

27. Navia BA, Price RW. The acquired immunodeficiency syndrome dementia complex as the presenting or sole manifestation of human immunodeficiency virus infection. Arch Neurol. 1987;44(1): 65-69.

28. Gray F, Geny C, Lionnet F, et al. Neuropathologic study of 135 adult cases of acquired immunodeficiency syndrome (AIDS). Ann Pathol. 1991;11(4):236-247.

29. Bouwman FH, Skolasky RL, Hes D, et al. Variable progression of HIV-associated dementia. Neurology. 1998;50(6):1814-1820.

30. Lezak MD, Howieson DB, Loring DW, Hannay HJ, Fischer JS. Neuropsychological Assessment. 4th ed. New York: Oxford University Press; 2004.

31. McArthur JC, Cohen BA, Selnes OA, et al. Low prevalence of neurological and neuropsychological abnormalities in otherwise healthy HIV-1-infected individuals: results from the multicenter AIDS Cohort Study. Ann Neurol. 1989;26(5):601-611.

32. McArthur JC, Selnes O. Human immunodeficiency virus-associated dementia. In: Berger JR, Levy RM, editors. AIDS and the Nervous System. 2nd ed. Philadelphia, PA: Lippincott-Raven; 1997: 527-567.

33. Butters N, Grant I, Haxby J, et al. Assessment of AIDS-related cognitive changes: recommendations of the NIMH workshop on neuropsychological assessment approaches. J Clin Exp Neuropsychol. 1990;12(6): 963-978.

34. Heaton RK, Miller SW, Taylor MJ, Grant I. Revised Comprehensive Norms for an Expanded Halstead-Reitan Battery: Demographically Adjusted Neuropsychological Norms for African American and Caucasian Adults. Lutz, FL: Psychological Assessment Resources; 2004.

35. Reitan RM, Wolfson D. The Halstead-Reitan Neuropsychological Test Battery: Theory and Clinical Interpretation. Tucson, AZ: Neuropsychology Press; 1993.

36. Power C, Selnes OA, Grim JA, McArthur JC. HIV Dementia Scale: a rapid screening test. J Acquir Immune Defic Syndr Hum Retrovirol. 1995;8(3):273-278.

37. Folstein MF, Folstein SE, McHugh PR. "Mini-mental state". A practical method for grading the cognitive state of patients for the clinician. J Psychiatr Res. 1975;12(3):189-198.

38. Lojek E, Bornstein RA. The stability of neurocognitive patterns in HIV infected men: classification considerations. J Clin Exp Neuropsychol. 2005;27(6):665-682.

39. Dawes S, Suarez P, Casey CY, et al; HNRC Group. Variable patterns of neuropsychological performance in HIV-1 infection. $J$ Clin Exp Neuropsychol. 2008;30(6):613-626.

40. Delis DC, Peavy G, Heaton RK, et al; HNRC Group. Do patients with HIV-associated minor cognitive/motor disorder exhibit a "subcortical" memory profile? Evidence using the California verbal learning test. Assessment. 1995;2(2):151-165. 
41. Carey CL, Woods SP, Rippeth JD, Heaton RK, Grant I; HIV Neurobehavioral Research Center (HNRC) Group. Prospective memory in HIV-1 infection. J Clin Exp Neuropsychol. 2006;28(4):536-548.

42. Martin EM, Nixon H, Pitrak DL, et al. Characteristics of prospective memory deficits in HIV-seropositive substance-dependent individuals: preliminary observations. J Clin Exp Neuropsychol. 2007;29(5): 496-504.

43. Woods SP, Moore DJ, Weber E, Grant I. Cognitive neuropsychology of HIV-associated neurocognitive disorders. Neuropsychol Rev 2009;19(2):152-168.

44. Reger M, Welsh R, Razani J, Martin DJ, Boone KB. A meta-analysis of the neuropsychological sequelae of HIV infection. J Int Neuropsychol Soc. 2002;8(3):410-424.

45. Bartok JA, Martin EM, Pitrak DL, et al. Working memory deficits in HIV-seropositive drug users. J Int Neuropsychol Soc. 1997;3(5):451-456.

46. Martin EM, Sullivan TS, Reed RA, et al. Auditory working memory in HIV-1 infection. J Int Neuropsychol Soc. 2001;7(1):20-26.

47. Perdices M, Cooper DA. Simple and choice reaction time in patients with human immunodeficiency virus infection. Ann Neurol. 1989; 25(5):460-467.

48. Tozzi V, Balestra P, Galgani S, et al. Positive and sustained effects of highly active antiretroviral therapy on HIV-1-associated neurocognitive impairment. AIDS. 1999;13(14):1889-1897.

49. Grant I, Atkinson JH, Hesselink JR, et al. Evidence for early central nervous system involvement in the acquired immunodeficiency syndrome (AIDS) and other human immunodeficiency virus (HIV) infections. Studies with neuropsychologic testing and magnetic resonance imaging. Ann Intern Med. 1987;107(6):828-836.

50. Wolters PL, Brouwers P, Civitello L, Moss HA. Receptive and expressive language function of children with symptomatic HIV infection and relationship with disease parameters: a longitudinal 24-month follow-up study. AIDS. 1997;11(9):1135-1144.

51. Levin BE, Berger JR, Didona T, Duncan R. Cognitive function in asymptomatic HIV-1 infection: the effects of age, education, ethnicity, and depression. Neuropsychology. 1992;6(4):303-313.

52. Stern RA, Silva SG, Chaisson N, Evans DL. Influence of cognitive reserve on neuropsychological functioning in asymptomatic human immunodeficiency virus-1 infection. Arch Neurol. 1996;53(2): $148-153$.

53. Blanchette N, Smith ML, King S, Fernandes-Penney A, Read S. Cognitive development in school-age children with vertically transmitted HIV infection. Dev Neuropsychol. 2002;21(3):223-241.

54. Green JE, Saveanu RV, Bornstein RA. The effect of previous alcohol abuse on cognitive function in HIV infection. Am J Psychiatry. 2004;161(2):249-254.

55. Iudicello JE, Woods SP, Parsons TD, Moran LM, Carey CL, Grant I. Verbal fluency in HIV infection: a meta-analytic review. J Int Neuropsychol Soc. 2007;13(1):183-189.

56. Woods SP, Morgan EE, Dawson M, Cobb Scott J, Grant I; HIV Neurobehavioral Research Center (HNRC) Group. Action (verb) fluency predicts dependence in instrumental activities of daily living in persons infected with HIV-1. J Clin Exp Neuropsychol. 2006;28(6): 1030-1042.

57. Cysique LA, Maruff P, Brew BJ. The neuropsychological profile of symptomatic AIDS and ADC patients in the pre-HAART era: a meta-analysis. J Int Neuropsychol Soc. 2006;12(3):368-382.

58. Hardy DJ, Hinkin CH. Reaction time performance in adults with HIV/AIDS. J Clin Exp Neuropsychol. 2002;24(7):912-929.

59. Sacktor NC, Skolasky RL, Lyles RH, Esposito D, Selnes OA, McArthur JC. Improvement in $\mathrm{HIV}$-associated motor slowing after antiretroviral therapy including protease inhibitors. J Neurovirol. 2000;6(1):84-88.

60. Foley J, Ettenhofer M, Wright M, Hinkin CH. Emerging issues in the neuropsychology of HIV infection. Curr HIV/AIDS Rep. 2008;5(4): 204-211.

61. Centers for Disease Control and Prevention. HIV prevalence estimates United States, 2006. MMWR Morb Mortal Wkly Rep. 2008;57(39): 1073-1076.
62. Van Gorp WG, Miller EN, Marcotte TD, et al. The relationship between age and cognitive impairment in HIV-1 infection: findings from the Multicenter AIDS Cohort Study and a clinical cohort. Neurology. 1994;44(5):929-935.

63. Cherner M, Ellis RJ, Lazzaretto D, et al; HIV Neurobehavioral Research Center Group. Effects of HIV-1 infection and aging on neurobehavioral functioning: preliminary findings. AIDS. 2004;18 Suppl 1:S27-S34.

64. Valcour VG, Shikuma CM, Watters MR, Sacktor NC. Cognitive impairment in older HIV-1-seropositive individuals: prevalence and potential mechanisms. AIDS. 2004;18 Suppl 1:S79-S86.

65. Van Gorp WG, Mitrushina M, Cummings JL, Satz P, Modesitt J. Normal aging and the subcortical encephalopathy of AIDS: a neuropsychological comparison. Neuropsychiatry Neuropsychol Behav Neurol. 1989;2(1):5-20.

66. Foley J, Ettenhofer M, Wright MJ, et al. Neurocognitive functioning in HIV-1 infection: effects of cerebrovascular risk factors and age. Clin Neuropsychol. 2010;24(2):265-285.

67. Wright EJ, Grund B, Robertson K, et al; INSIGHT SMART Study Group. Cardiovascular risk factors associated with lower baseline cognitive performance in HIV-positive persons. Neurology. 2010; 75(10):864-873.

68. Bergersen BM. Cardiovascular risk in patients with HIV infection: impact of antiretroviral therapy. Drugs. 2006;66(15):1971-1987.

69. Friis-Møller N, Sabin CA, Weber R, et al; Data Collection on Adverse Events of Anti-HIV Drugs (DAD) Study Group. Combination antiretroviral therapy and the risk of myocardial infarction. $N$ Engl J Med. 2003;349(21):1993-2003.

70. Sherman KE, Rouster SD, Chung RT, Rajicic N. Hepatitis C virus prevalence among patients infected with human immunodeficiency virus: a cross-sectional analysis of the US adult AIDS Clinical Trials Group. Clin Infect Dis. 2002;34(6):831-837.

71. Van Gorp WG, Lamb DG, Schmitt FA. Methodologic issues in neuropsychological research with HIV-spectrum disease. Arch Clin Neuropsychol. 1993;8(1):17-33.

72. Centers for Disease Control and Prevention. Coinfection with HIV and hepatitis C virus. 2005. Available from: http://www.cdc.gov/hiv/ resources/factsheets/PDF/coinfection.pdf. Accessed September 27, 2010.

73. Paul R, Letendre S, Dearborn J. Impact of hepatitis C coinfection on cognitive outcomes in HIV-infected individuals. Curr Hepatitis Rep. 2007;6(4):145-152.

74. Perry W, Carlson MD, Barakat F, et al. Neuropsychological test performance in patients co-infected with hepatitis $\mathrm{C}$ virus and HIV. AIDS. 2005;19 Suppl 3:S79-S84.

75. Nath A, Hauser KF, Wojna V, et al. Molecular basis for interactions of HIV and drugs of abuse. J Acquir Immune Defic Syndr. 2002; 31 Supp1 2:S62-S69.

76. Nath A, Maragos WF, Avison MJ, Schmitt FA, Berger JR. Acceleration of HIV dementia with methamphetamine and cocaine. J Neurovirol. 2001;7(1):66-71.

77. Nath A, Anderson C, Jones M, et al. Neurotoxicity and dysfunction of dopaminergic systems associated with AIDS dementia. J Psychopharmacol. 2000;14(3):222-227.

78. Bell JE, Brettle RP, Chiswick A, Simmonds P. HIV encephalitis, proviral load and dementia in drug users and homosexuals with AIDS. Effect of neocortical involvement. Brain. 1998;121(Pt 11): 2043-2052.

79. Reyes MG, Faraldi F, Senseng CS, Flowers C, Fariello R. Nigral degeneration in acquired immune deficiency syndrome (AIDS). Acta Neuropathol. 1991;82(1):39-44.

80. Atkinson JH Jr, Grant I, Kennedy CJ, Richman DD, Spector SA, McCutchan JA. Prevalence of psychiatric disorders among men infected with human immunodeficiency virus. A controlled study. Arch Gen Psychiatry. 1988;45(9):859-864.

81. Dubé B, Benton T, Cruess DG, Evans DL. Neuropsychiatric manifestations of HIV infection and AIDS. J Psychiatry Neurosci. 2005; 30(4):237-246. 
82. Ickovics JR, Hamburger ME, Vlahov D, et al; HIV Epidemiology Research Study Group. Mortality, CD4 cell count decline, and depressive symptoms among HIV-seropositive women: longitudinal analysis from the HIV Epidemiology Research Study. JAMA. 2001;285(11): $1466-1474$.

83. Gibbie T, Mijch A, Ellen S, et al. Depression and neurocognitive performance in individuals with HIV/AIDS: 2-year follow-up. HIV Med. 2006;7(2):112-121.

84. Farinpour R, Miller EN, Satz P, et al. Psychosocial risk factors of HIV morbidity and mortality: findings from the Multicenter AIDS Cohort Study (MACS). J Clin Exp Neuropsychol. 2003;25(5):654-670.

85. Adler NE, Boyce T, Chesney MA, et al. Socioeconomic status and health. The challenge of the gradient. Am Psychol. 1994;49(1):15-24.

86. Smedley BD, Stith AY, Nelson AR, editors. Unequal Treatment: Confronting Racial and Ethnic Disparities in Health Care. Washington (DC): The National Academies Press; 2003.

87. Fox JW. Mothers' influence on their adolescents' tendency to seek medical care. J Adolesc Health. 1991;12(2):116-123.

88. Stern Y. What is cognitive reserve? Theory and research application of the reserve concept. J Int Neuropsychol Soc. 2002;8(3):448-460.

89. Stern Y. Cognitive reserve. Neuropsychologia. 2009;47(10): 2015-2028.

90. Brew BJ, Letendre SL. Biomarkers of HIV related central nervous system disease. Int Rev Psychiatry. 2008;20(1):73-88.

91. Brew BJ. Markers of AIDS dementia complex: the role of cerebrospinal fluid assays. AIDS. 2001;15(14):1883-1884.

92. Avison MJ, Nath A, Berger JR. Understanding pathogenesis and treatment of HIV dementia: a role for magnetic resonance? Trends Neurosci. 2002;25(9):468-473.

93. Aylward EH, Brettschneider PD, McArthur JC, et al. Magnetic resonance imaging measurement of gray matter volume reductions in HIV dementia. Am J Psychiatry. 1995;152(7):987-994.

94. Dal Pan GJ, McArthur JH, Aylward E, et al. Patterns of cerebral atrophy in HIV-1-infected individuals: results of a quantitative MRI analysis. Neurology. 1992;42(11):2125-2130.

95. Stout JC, Ellis RJ, Jernigan TL, et al. Progressive cerebral volume loss in human immunodeficiency virus infection: a longitudinal volumetric magnetic resonance imaging study. HIV Neurobehavioral Research Center Group. Arch Neurol. 1998;55(2):161-168.

96. Kieburtz KD, Ketonen L, Zettelmaier AE, Kido D, Caine ED, Simon JH. Magnetic resonance imaging findings in HIV cognitive impairment. Arch Neurol. 1990;47(6):643-645.

97. Avison MJ, Nath A, Greene-Avison R, Schmitt FA, Greenberg RN, Berger JR. Neuroimaging correlates of HIV-associated BBB compromise. J Neuroimmunol. 2004;157(1-2):140-146.
98. Roc AC, Ances BM, Chawla S, et al. Detection of human immunodeficiency virus induced inflammation and oxidative stress in lenticular nuclei with magnetic resonance spectroscopy despite antiretroviral therapy. Arch Neurol. 2007;64(9):1249-1257.

99. Mohamed MA, Lentz MR, Lee V, et al. Factor analysis of proton MR spectroscopic imaging data in HIV infection: metabolite-derived factors help identify infection and dementia. Radiology. 2010;254(2): 577-586.

100. Panel on Antiretroviral Guidelines for Adults and Adolescents. Guidelines for the Use of Antiretroviral Agents in HIV-1 Infected Adults and Adolescents. Washington, DC: US Department of Health and Human Services; December 1, 2009.

101. Abbas AK, Lichtman AH. Basic Immunology. 3rd ed. Philadelphia, PA: Elsevier Saunders; 2011.

102. Letendre S, Marquie-Beck J, Capparelli E, et al; CHARTER Group. Validation of the CNS penetration-effectiveness rank for quantifying antiretroviral penetration into the central nervous system. Arch Neurol. 2008;65(1):65-70

103. Patel K, Ming X, Williams PL, Robertson KR, Oleske JM, Seage GR 3rd; International Maternal Pediatric Adolescent AIDS Clinical Trials 219/219C Study Team. Impact of HAART and CNS-penetrating antiretroviral regimens on HIV encephalopathy among perinatally infected children and adolescents. AIDS. 2009;23(14):1893-1901.

104. Letendre SL, McCutchan JA, Childers ME, et al; HNRC Group. Enhancing antiretroviral therapy for human immunodeficiency virus cognitive disorders. Ann Neurol. 2004;56(3):416-423.

105. Liner J, Meeker RB, Robertson K. CNS toxicity of antiretroviral drugs. 17th Conference on Retroviruses and Opportunistic Infections; 2010 Feb 16-19; San Francisco, CA, USA.

106. Winston A, Duncombe C, Li PC, et al; Altair Study Group. Does choice of combination antiretroviral therapy (cART) alter changes in cerebral function testing after 48 weeks in treatment-naive, HIV-1infected individuals commencing cART? A randomized, controlled study. Clin Infect Dis. 2010;50(6):920-929.

107. Ances BM, Ellis RJ. Dementia and neurocognitive disorders due to HIV-1 infection. Semin Neurol. 2007;27(1):86-92.

108. Schifitto G, Navia BA, Yiannoutsos CT, et al; Adult AIDS Clinical Trial Group (ACTG) 301; 700 Teams; HIV MRS Consortium. Memantine and HIV-associated cognitive impairment: a neuropsychological and proton magnetic resonance spectroscopy study. AIDS. 2007;21(14):1877-1886.
Neurobehavioral HIV Medicine

\section{Publish your work in this journal}

Neurobehavioral HIV Medicine is an international, peer-reviewed, open access journal focusing on advances in research in HIV/ AIDS, with specific reference to the neurological, psychiatric and behavioral consequences of the disease, concomitant infections and specific antiretroviral therapy. The manuscript management

\section{Dovepress}

system is completely online and includes a very quick and fair peer-review system, which is all easy to use. Visit http://www. dovepress.com/testimonials.php to read real quotes from published authors. 